\title{
Periodismo deportivo. Nuevas tendencias y perspectivas de futuro
}

Recibido: 02 de noviembre de 2013

Aceptado: 01 de septiembre de 2014

Publicado: 28 de noviembre de 2014
José Luis Rojas Torrijos

jlrojas@us.es

Universidad de Sevilla (España)

Resumen: El periodismo deportivo sobresale como una modalidad informativa de alto impacto social por la universalidad de la materia abordada y, al mismo tiempo, por su gran arraigo intranacional. Esta área informativa atraviesa por un momento de expansión con el nacimiento en los últimos años de nuevos medios de comunicación especializados en los diferentes soportes, y con ello también una transformación en su estructura. Este campo periodístico se ha convertido en un terreno innovador y de extraordinario dinamismo, caracterizado por su continua exploración de nuevas formas de contar historias aprovechando las nuevas tecnologías digitales. Este artículo analiza algunas de las últimas tendencias en periodismo deportivo, que están llamadas a mostrar el camino para los años venideros, como son las nuevas narrativas multimedia e interactivas y los textos informativos de largo formato.

Palabras clave: Periodismo deportivo, nuevo periodismo, nuevas narrativas digitales, largo formato, periodismo de datos.

Abstract: Sports journalism stands out as a form of reporting of high social impact due to
the universality of sport and also because of its deep-rooted intranational significance. This
journalistic field runs through a moment of flourishing where new specialized media in the
different platforms were born and thereby a profound transformation in their structures.
This kind of journalism has become an innovative and extremely dynamic area, defined by
its continuous exploration of new ways of storytelling embracing new digital technologies.
This article focuses on some of the latest trends in sports journalism, which are claimed to
show the way for the following years like new multimedia, interactives, data journalism or
longform features.

Key words: Sports Journalism, New Journalism, New Interactive Storytelling, Long Form Journalism, Data Journalism. 


\section{Introducción: El periodismo de mayor impacto social}

El periodismo deportivo ha vivido en las últimas décadas un notabilísimo desarrollo en sus estructuras, canales y modos de producir contenidos, y ha cobrado un creciente protagonismo hasta afianzarse en el momento actual como la tipología informativa de mayor alcance social en una buena parte de los países tanto europeos como americanos. El florecimiento de esta tipología informativa no solo ha sido numérico; lo ha hecho marcando tendencias, creando un estilo propio, fundamentado en el color, la originalidad y la espectacularidad de sus propuestas, y aportando un nuevo modelo de presentación de las informaciones a través de un lenguaje que es visualmente atractivo y resulta común y accesible para todas las mentalidades.

Tal como explica Alcoba (2005: 10), el florecimiento de este tipo de periodismo especializado se fundamenta en gran medida en el hecho de que los profesionales de estos medios "informan de un género específico comprensible a todas las mentalidades a través de un lenguaje universal que todos entienden, producto del espíritu y la filosofía del deporte, como fenómeno cultural más seguido y practicado desde comienzos del siglo pasado y que va en aumento en el siglo que hemos iniciado".

Este auge ha propiciado que en nuestros días el periodismo deportivo sea una parcela de estudio de importancia creciente y que, cada vez más, adquiera un mayor reconocimiento dentro del mundo mediático (donde los reporteros deportivos ya no son vistos como outsiders) y de los ámbitos cultural y académico, a diferencia de antaño. De esta forma, ha logrado liberarse del contraste de ser al mismo tiempo la tipología informativa de mayor éxito social y un área periodística estigmatizada y asociada a campos de poco prestigio. Ya se ha ganado el respeto de la academia (Wanta, 2013: 83-84).

Además de esta visión contradictoria que suscita el periodismo deportivo, llama la atención su naturaleza, al tratarse de una modalidad cuyo alto impacto tiene que ver tanto con la universalidad de la materia sobre la que trata como con su profundo arraigo intranacional. El deporte no sólo se constituye actualmente como el producto informativo de mayor interés colectivo y éxito social en la mayoría de los lugares, sino que además ha sido capaz de expandirse y evolucionar forjando estrechos vínculos con la comunidad de habitantes a la que pertenece y se dirige, ya sea una ciudad, una región o un país. Cumple así su función de constituirse como "un instrumento civilizador y constructor del tejido social" (Hernández, Osorio y Zapata, 2013: 219).

No se trata, en cualquier caso, de un fenómeno reciente, sino más bien ligado a la historia del deporte-espectáculo desde inicios del siglo XX. El nexo entre medios de comunicación y deporte ha sido decisivo para la conformación de las identidades nacionales (Rowe, 2013).

"El poder de atracción que tiene el deporte ha sido históricamente muy bien aprovechado por el periodismo, que ha proyectado los logros de deportistas y equipos hacia la comunidad a la que representan mientras ha despertado en el ciudadano la necesidad de consumir ese 
tipo de información para ser partícipe de la consecución de un éxito colectivo. De esta forma, el periodismo deportivo se ha convertido en un elemento de cohesión de las sociedades contemporáneas a las que presta un servicio público y con las que se identifica cultural y emocionalmente" (Rojas, 2011: 17).

Efectivamente, el periodismo especializado en deportes contribuye a intensificar esa sensación de pertenencia a una comunidad y de complicidad y proximidad con sus conciudadanos, a los que involucra en la celebración de los logros de los deportistas y equipos nacionales en competiciones sobre las que informa. Este hecho se pone de manifiesto sobre todo en los eventos de ámbito internacional y de máxima repercusión, como los Mundiales de fútbol o los Juegos Olímpicos, citas que están marcadas en rojo en la agenda temática y van acompañadas de grandes despliegues informativos al mismo tiempo que sirven para pulsar el grado de cohesión interna y el sentimiento nacional de los territorios.

El periodismo en este sentido ha desempeñado históricamente un papel clave en la creación y consolidación de los grandes acontecimientos deportivos internacionales porque ha sido y es un agente implicado en su desarrollo, es parte contratante de este negocio. Hasta tal punto es así que actualmente la influencia de los medios, especialmente de la televisión, es decisiva para la configuración de los calendarios que diseñan organismos internacionales como la FIFA o el Comité Olímpico Internacional. Estos ajustan las fechas, horarios e incluso reglamentos de las competiciones (por ejemplo, las interrupciones en fútbol americano para dar cabida en los canales a los espacios publicitarios) a las necesidades de las cadenas, que han pagado cantidades millonarias por los derechos de emisión de los encuentros deportivos, los espacios más vistos y los que mayor número de anunciantes atraen (Andrews, 2005: 118).

No obstante, a pesar de poseer una dimensión intrínsecamente local o nacional, el deporte se ha consolidado como un fenómeno de naturaleza global, fundamentalmente por el alcance y el seguimiento de las retransmisiones televisivas y, más recientemente, como consecuencia del desarrollo imparable del nuevo entorno 2.0, webs, blogs y redes sociales en tanto que plataformas universales de producción de contenidos.

Tal como asevera Boyle (2006: 3), "el periodismo deportivo ofrece un fascinante caso de estudio para comprobar cómo los medios de comunicación globales y locales interactúan en las sociedades contemporáneas. El deporte en ocasiones puede mostrarse como universal y mirar hacia el exterior o puede también tener un enfoque local y responder a unas preocupaciones profundamente domésticas".

Lo cierto es que, más allá de esta doble dimensión, universal e intranacional, el periodismo deportivo ha evolucionado hasta convertirse en la actualidad en el producto informativo de mayor alcance social y en el más demandado y consumido en muchos países de la Europa Meridional y América Latina, tanto en la prensa tradicional, en los medios radiofónicos y televisivos, como en los nuevos soportes digitales. 
La programación deportiva constituye uno de los pilares que conforman la oferta de programación de las principales cadenas de radio y televisión, ya que sus espacios se han consagrado en los últimos tiempos como los más escuchados o vistos $\mathrm{y}$, por tanto, como los más codiciados por las empresas periodísticas para captar audiencia y, con ello, publicidad, a través sobre todo de las retransmisiones en directo de competiciones deportivas.

"En los medios audiovisuales, el deporte se ha convertido en un verdadero espectáculo de masas donde la información queda supeditada al entretenimiento como forma de expresión y en cuyo discurso se han incorporado elementos ajenos al ámbito del periodismo al formar parte de una estrategia comercial enfocada hacia la rentabilidad económica y la generación de negocio" (Rojas, 2013: 238).

La pujanza del periodismo deportivo es especialmente significativa en el ámbito de la prensa, donde esta área informativa se comporta como una de las secciones estrella de los diarios de referencia y mayor prestigio a ambos lados del Atlántico y, al mismo tiempo, se ha convertido en la parcela del periodismo especializado que cuenta con un mayor número de cabeceras.

Así, por ejemplo, vemos cómo en España conviven hasta cuatro periódicos de difusión nacional (Marca, As, Sport, Mundo Deportivo) con otros cuatro de ámbito regional (Superdeporte, Estadio Deportivo, Campeón y El 9 Esportiu), tres en Italia (La Gazzetta dello Sport, decano de la prensa deportiva europea, 1896; Tuttosport y Corriere dello Sport Stadio), al igual que en Portugal ( $A$ Bola, O Jogo, Record), mientras que hay uno en Francia ( $L$ 'Equipe). También hay prensa deportiva diaria en Grecia, Turquía y Rumanía. En Europa, fuera del ámbito mediterráneo, la información deportiva especializada queda circunscrita a publicaciones semanales o mensuales, como son los casos de Kicker (Alemania), Voetbal International (Holanda) y diferentes publicaciones en el Reino Unido (Four Four Two, The Green Soccer Journal o The Blizzard). Todos estos medios se unen a otros semanarios de gran tradición como Guerin Sportivo (Italia) o France Football (Francia).

Entretanto, la eclosión de la prensa deportiva ha sido aún mayor si cabe en Latinoamérica, donde multitud de nuevas publicaciones se han sumado a una relación de rotativos especializados de gran tradición y arraigo popular. Así en los últimos años han surgido los primeros periódicos deportivos en varios países como Costa Rica (Al Día), Honduras (Diez) o El Salvador (El Gráfico) y han aumentado en otros, como en Venezuela, donde Lider coexiste con Meridiano; México, con Récord, La Afición y Estadio Deportes, que compiten con los más antiguos, Esto y Ovaciones; o Perú, un mercado en el que hay cuatro diarios especializados (Depor, Todo Sport, Líbero y El Bocón); o, más recientemente, Marca, que abrió redacción en Colombia, donde también está El Periódico Deportivo. En Argentina, donde abrió paso en 1919 la casi centenaria revista El Gráfico, solo hay un diario deportivo, Olé (Grupo Clarín); una situación similar a la de Brasil, con el diario Lance y la revista mensual Placar. En la gran mayoría de estos títulos, se concede prioridad absoluta al fútbol, salvo las publicaciones de países caribeños, donde el béisbol es el deporte rey. 
Vemos, por tanto, cómo la prensa deportiva de papel se ha desarrollado de forma extraordinaria en ambos continentes y sigue ocupando un lugar destacado en el mercado periodístico a pesar del avance imparable de las nuevas tecnologías y la apuesta decidida de muchas empresas periodísticas por reforzar sus sitios digitales de noticias para ganar en competitividad y hacer frente a las nuevos requerimientos y hábitos de consumo del público receptor.

\section{Un escenario digital cambiante}

La aparición de Internet ha transformado la manera de producir noticias y está produciendo un cambio de fisonomía de las redacciones periodísticas. En medio del nuevo escenario digital, el periodismo ha encontrado en el entorno 2.0., en los blogs y, muy especialmente, en los social media uno de sus principales y más eficaces vectores de difusión de contenidos, hasta el punto de convertirse en el canal más rápido y eficaz para anunciar todo tipo de noticias superando en velocidad a los flashes de agencia.

Cada vez más, las redes sociales como Twitter se están imponiendo como la plataforma preferida por servicios de noticias para ofrecer avances de primicias informativas y, consecuentemente, se erigen como una de las fuentes de información principales para el resto de medios de convencionales. La red de microblogging se anticipa a la noticia que luego será desarrollada y ampliada en webs, emisoras de radio, programas de televisión y páginas de periódico.

Twitter ha modificado también la rutina diaria del informador deportivo, que encuentra en este nuevo canal muchas más posibilidades que antes para interactuar con sus receptores, para reforzar su marca periodística personal y para tener un mayor feedback, útil para encontrar otras noticias y nuevas historias que contar, y hacerlo de la forma más adecuada para incrementar su audiencia y generar un mayor tráfico a la web (Matthews y Anwar, 2013: 304).

Tal como señala Jay Rosen, de todas las características del periodismo en Internet hay dos que destacan claramente sobre las demás y son las que de verdad están marcando las pautas de trabajo en las redacciones y la respuesta de los lectores-usuarios: "La primera es que las noticias se pueden actualizar constantemente, y esa capacidad para informar con la mayor rapidez es uno de los puntos clave -aunque no el único- del éxito de los cibermedios que tienen un número más alto de visitas. La segunda, y no por eso menos importante, es que la audiencia ha dejado de ser pasiva" (ápud Edo, 2009: 4-5).

Toda esta irrupción de la nueva realidad digital también ha tenido incidencia en la evolución del periodismo deportivo. Por un lado, el crecimiento de Internet ha propiciado el nacimiento de nuevos medios digitales dedicados a este tipo de información, que han aprovechado el poderoso alcance de las nuevas plataformas para cubrir con mayor especialización el fútbol y el resto de modalidades y satisfacer así necesidades informativas de la audiencia que no estaban siendo cubiertas por los medios convencionales. 
Por otra parte, la aceleración en los procesos de producción de noticias que marca la red ha obligado a que los "viejos" medios, especialmente los impresos, replanteen sus contenidos y coberturas: con la última hora ya ofrecida por sus propias ediciones digitales, al papel le queda reorientarse hacia un mayor análisis, una mayor profundidad en el tratamiento de la información y la búsqueda de temas propios y grandes historias. A este respecto Ferrara (2014) considera que escribir sobre deportes ha cambiado para siempre; hacerlo hoy es ofrecer contenidos más trabajados que vayan más allá de los partidos y de las urgencias que rodean directamente a la alta competición; es aprender a hacer coberturas más amplias y cultivar fuentes primarias que abran la vía a reportajes o entrevistas.

\subsection{Periodismo deportivo emprendedor}

Efectivamente, el periodismo deportivo no es ajeno al complejo proceso de cambios y de reestructuración al que está sometido en la actualidad al conjunto del sector de los medios de comunicación, los cuales han de ir adaptándose necesariamente a la continua evolución del mercado para no dejar de ser competitivos. La obligada reconversión hacia lo digital ha traído consigo la incorporación de nuevas herramientas tecnológicas aplicadas a las tareas periodísticas y, como consecuencia de ello, una transición hacia nuevos perfiles profesionales, que, además de contar noticias, han de poseer competencias adicionales en otras labores como programación, fotoperiodismo, videoedición o infografía. Empieza a imponerse el periodista multitarea o multifunción, el también llamado "hombre orquesta".

Uno de los sectores periodísticos que está atravesando mayores ajustes estructurales es el deportivo. En países como España, las empresas editoras de periódicos, debido al gran volumen de espacios deportivos que ofrece la televisión, la inmediatez que sigue aportando la radio y la incidencia de una caída de las ventas en los quioscos y de anunciantes en general, han iniciado un proceso de reducción de plantillas y están concentrando sus esfuerzos en la expansión de su marca a través de Internet. De esta forma, se encaminan hacia un producto más ágil y dinámico con el que responder eficazmente a la máxima actualidad y, de paso, complementar y proyectar sus respectivos productos de papel con contenidos digitales nuevos y diferenciados.

Pese a este esfuerzo por hacer un producto cada vez más multimedia a partir de la convergencia tecnológica y integración de la redacción convencional y la digital (Salaverría y García Avilés: 2008), uno de los mayores desafíos que ha de afrontar el periodismo deportivo tradicional reside en cómo adaptarse a la continua migración de lectores que prefieren buscar noticias en los soportes digitales antes que en el papel. Este paso se ha acelerado en los últimos tiempos gracias a la aparición de nuevos dispositivos tecnológicos, como los teléfonos inteligentes, las tabletas y iPads con sus respectivas aplicaciones, que permiten que cualquier ciudadano en cualquier lugar pueda acceder al instante a los últimos resultados o declaraciones de su equipo o de su deportista favorito, solo con pasar el dedo por la pantalla. El periodismo ha de estar allí donde está la gente.

La verdadera revolución periodística provocada tras la irrupción de Internet no solo ha obligado a los medios impresos, radiofónicos y televisivos tradicionales a reforzar su 
presencia online con portales y webs cada vez más actualizadas, interactivas y con mayor número de contenidos multimedia, blogs y hemerotecas en línea. También ha supuesto la proliferación de medios deportivos exclusivamente digitales, que, cuentan en muchos casos con un grado de especialización mucho mayor y compiten con productos propios $\mathrm{y}$ diferenciados.

Como señalábamos antes, el periodismo deportivo digital ha encontrado una vía de propagación aún mayor gracias a las principales redes sociales. Así, a través de sus cuentas oficiales o de algunos de sus profesionales y blogueros más relevantes, los medios logran dar una mayor difusión a sus contenidos mediante enlaces a noticias, reportajes, vídeos o artículos de opinión que, de forma viral, conducen a aumentar el tráfico de visitas hacia sus respectivas webs. Los blogs y las redes sociales se erigen así en nuevas fuentes para los periodistas deportivos al incluir espacios de participación para que los ciudadanos se impliquen más y comenten noticias publicadas, hagan sugerencias y correcciones, e incluso aporten datos y documentos a partir de los cuales los profesionales puedan pulsar mejor el sentir popular y, a partir de ahí, amoldar con acierto sus mensajes.

Entre los nuevos medios deportivos que han nacido últimamente, destacan aquellos que han sido creados o que están integrados por un reducido número de periodistas de una larga trayectoria en secciones deportivas de medios tradicionales o en diarios especializados y que han decidido dar el salto a la red para avanzar profesionalmente. Se trata de proyectos periodísticos emprendedores que han tomado el rumbo hacia la especialización deportiva y lo hacen con el aval de la experiencia, de las fuentes y los contactos, de unos profesionales que han sido despedidos o se han visto obligados a abandonar sus medios después de muchos años.

Esta ola emprendedora tiene su punta de lanza en el periodismo deportivo, un campo en el que no dejan de ver la luz nuevos medios, micromedios y proyectos, con intereses y enfoques distintos pero con un denominador común: la búsqueda de la diferenciación y la reclamación de un espacio propio y original para temáticas y protagonistas que no siempre tienen cabida (ni probablemente la tengan nunca) en los medios de comunicación tradicionales.

Así queda reflejado en el Informe Anual de la Profesión Periodística, publicado en diciembre de 2013 por la Asociación de la Prensa de Madrid (APM). Esta obra señala al periodismo deportivo como uno de los campos informativos más emprendedores con alrededor del 10\% de los 297 nuevos medios digitales, impresos y audiovisuales puestos en marcha por profesionales en España desde el año 2008.

De estos medios, la mayor parte son digitales, tanto aquellos cuyos contenidos tienen alcance nacional como, especialmente, los que se dirigen a un público más cercano, local o provincial (Eldeporteconquense, Oncecontraonce, Canariasbasket o Campdesports). Los primeros siguen la estela de medios como Sportyou (2008); los últimos toman el relevo de otras webs pioneras en este campo como Cordobadeporte, fundada en 2000, o Muchodeporte, creada en 2001 en Sevilla. 
Además de estos nuevos medios en Internet, el periodismo deportivo emprendedor ha avanzado también en el soporte papel con la aparición de publicaciones superespecializadas, que han apostado por formatos largos, un diseño original y unos contenidos de calidad al contar con la aportación de firmas ilustres. En este sentido, sobresalen las revistas futbolísticas Proyecto Panenka y Líbero, el gratuito Alirón o Cuadernos de Basket, medio de carácter trimestral sobre el deporte de la canasta.

Otros nacieron impresos y se han reconvertido a digitales, como la publicación multideporte Quality Sport o el magazine Protagonistas, primer medio en España dedicado exclusivamente al fútbol femenino. Al mismo tiempo, cobra cada vez mayor relevancia el desarrollo de servicios complementarios a la web o el producto impreso con soluciones adaptadas a los dispositivos móviles (Eleven Foot, Quality Sport, Minuto 116 o Metadeporte).

En otros países latinoamericanos, también han surgido nuevas voces en este ámbito periodístico, tales como la web polideportiva venezolana Letrasdeporte o la revista argentina Don Julio, que reivindica un género clásico y no siempre bien cuidado, como es la crónica de fútbol, siguiendo una corriente que se proyecta más allá del deporte con medios como Revista Anfibia, Tucumán Zeta, Nos Digital o El Puercoespín, y que también revive en las webs deportivas de medios generalistas como "Canchallena" de La Nación a través de los relatos y artículos del periodista Ezequiel Fernández Moores.

\subsection{Nuevos formatos}

Para lograr reorientar adecuadamente sus productos a las posibilidades de los nuevos soportes digitales y a unos hábitos de consumo del público usuario que están cambiando de forma significativa, el periodismo deportivo está apostando por nuevos formatos informativos. Entre ellos, sobresalen los elementos para la representación visual de los contenidos como gráficos, vídeos y reportajes multimedia, el periodismo de datos, así como las piezas narrativas de larga extensión.

\subsubsection{Elementos para la representación visual de los contenidos}

El periodismo deportivo deposita gran parte de su fortaleza en el carácter visual de sus contenidos. Tanto en el diseño de las webs como en la diagramación de las páginas impresas, este tipo de periodismo ha sabido siempre innovar para hacer más atractivos sus textos y atrapar la atención de los lectores a través de fotografías espectaculares, titulares de grandes dimensiones, infográficos singulares $\mathrm{y}$, últimamente, mediante otros elementos multimedia que completan la representación visual y sonora de los datos que se producen en las competiciones.

Estos nuevos gráficos se han convertido en uno de los principales reclamos de las webs periodísticas sobre deporte y en uno de los recursos informativos más eficaces para explicar o expresar los diferentes aspectos de un torneo o de un partido por medio de números, tablas, ilustraciones y elementos multimedia (vídeo, audio y fotos); todo de una manera sencilla, seductora y rentable en términos de espacio. 
Las infografías cumplen a la perfección su cometido, y por eso son cada vez más utilizadas, porque contienen (en un espacio más o menos reducido) un importante volumen de datos, tales como el número de participantes desagregados por sexo y nacionalidades, el formato de competición y el calendario con sus fechas, la historia o palmarés, $\mathrm{y}$, sobre todo, cuando se trata de deportes menos conocidos por el gran público, aspectos relacionados con el reglamento (infracciones, posiciones en el campo, dimensiones del terreno de juego, etcétera).

Debido al elevado número de datos que generan los acontecimientos deportivos, el periodismo encuentra en la infografía una nueva forma de narrar el deporte y de hacerlo mucho más accesible y a la vez sugerente. Los infográficos deportivos constituyen representaciones visuales de torneos y modalidades que, con carácter general, serían mucho más difíciles de comprender si solo se explicaran mediante texto. Sirven al periodismo para cumplir mejor sus funciones informativa y divulgativa al acercar el conocimiento del deporte en su diversidad al conjunto de la ciudadanía.

Otro elemento clave dentro de la nueva estrategia del periodismo deportivo para competir en el espacio digital frente a otras fuentes como la televisión es la dotación de secciones o sitios de vídeo-noticias. Estos, por un lado, ofrecen información actualizada de las competiciones, con las jugadas más sobresalientes de cada partido $\mathrm{y}$, por otro, incentivan la participación y refuerzan los lazos de fidelidad de sus lectores-usuarios a través de continuos enlaces en redes sociales y del alojamiento en canales específicos de YouTube.

El consumo de contenidos audiovisuales aumenta. En este sentido, el vídeo se está imponiendo como una parte esencial de la nueva manera de informar en las plataformas digitales, con imágenes más o menos impactantes y de corta duración, alrededor de un minuto, el tiempo preciso para contener los datos esenciales de la información y mantener la atención del público.

Por otra parte, estos vídeos, para los cuales los portales informativos están desarrollando aplicaciones para que sean vistos en los dispositivos móviles y puedan ser compartidos de forma masiva en todas las plataformas (Ramos: 2014), se han convertido en una importante fuente de ingresos para los medios, tanto a la hora de conseguir suscriptores como de captar anunciantes. Suelen contar con espacios patrocinados, como es el caso de 'Minute' en The New York Times, o bien sirven de gancho para comercializar el paquete de contenidos de pago de algunos medios, como son los resúmenes de la Premier League en la oferta del británico The Sun.

Junto con estos vídeos informativos breves, los sitios de noticias están profundizando en el streaming para la emisión en directo de eventos, así como en audiovisuales de larga duración (Pellicer: 2014). Mientras la mayoría de los medios ya cuentan con canales específicos en YouTube, la mayor plataforma de alojamiento de vídeos del mundo, otros han decidido crear su propia web televisión, un sitio con audiovisuales de producción propia que sirven o comercializan a otros medios a modo de agencia.

El aprovechamiento de las nuevas tecnologías para contar de otra forma las historias de siempre tiene su máxima expresión en los reportajes multimedia, especiales interactivos 
de gran calidad, tanto desde un punto de vista estético como en su acabado literario, los cuales combinan en una misma pieza desde hipertextos documentales, gráficos animados, infografías estáticas, fotografías panorámicas en alta resolución, vídeos inéditos hasta podcasts que transcriben o amplían los cuerpos de texto al formato audio.

Suelen ocuparse de grandes temas, con percha de actualidad pero concebidos para no perder vigencia y permanecer en el tiempo, y cuentan con un diseño propio y diferenciado respecto al aspecto general del sitio web al que pertenecen. Aparecen así como trabajos independientes, por lo que en ocasiones necesitan recordar en su encabezamiento las marcas visuales identificadoras del medio del que proceden.

Como afirma Marrero (2008), el reportaje multimedia, "más que un nuevo género periodístico, constituye la adaptación del reportaje al un nuevo medio de comunicación", aprovechando las tres principales cualidades comunicativas de la red, la hipertextualidad, la interactividad y la multimedialidad para hacer efectiva su renovación:

"Es en la integración de estos tres atributos donde descansa el punto de mayor redimensionamiento del género. Un reportaje que logre aprovechar al máximo y combinar la estructuración hipertextual con los recursos multimediales e interactivos, pasa a ser un mensaje periodístico fértil, no sólo por sus posibilidades interpretativas o por el tratamiento narrativo complejo que puede incluir, sino por su contenido humano, por la fuerza que posee el género para conmover y movilizar la opinión de los receptores, para denunciar lo que permanece oculto, para instruir".

\subsubsection{Periodismo deportivo de datos}

Hay pocas áreas de la comunicación periodística donde se manejen más estadísticas que en el deporte. De hecho, muy pocas crónicas están desprovistas de ese conjunto de datos que resumen el partido (Marrero Rivera, 2011: 131). La estadística se ha integrado en el deporte de manera permanente porque es la manera de explicar o expresar los diferentes aspectos de una competición o de un partido por medio de números. Dichas cifras buscan ofrecer al aficionado una visión lo más clara posible de lo ocurrido y de la participación de cada jugador o deportista. También sirve a los propios técnicos y entrenadores de los equipos porque es una forma de saber quién ha jugado mejor y en qué facetas del juego debe mejorar el equipo o el deportista con vistas al futuro.

Los datos estadísticos pueden hacer referencia exclusiva a un partido o pueden ser acumulativos de toda una temporada, de una etapa o de toda una trayectoria profesional (las llamadas "series históricas"). Pueden, por tanto, explicar un aspecto específico de un partido (rebotes y porcentajes de tiro en baloncesto, errores no forzados en tenis o porcentajes de posesión del balón en fútbol) o el mismo aspecto referido a un periodo de tiempo más amplio. 
Por tanto, el deporte es un terreno donde las estadísticas son consustanciales al relato periodístico para explicar lo sucedido en las competiciones, y esto ha hecho que los medios de comunicación hayan apostado, cada vez más y de forma mucho más evidente en los soportes digitales, por ilustrar las informaciones con un número creciente de gráficos y visualizaciones de datos.

En los medios digitales y webs de medios impresos y audiovisuales, los gráficos incorporan, además, todas las posibilidades interactivas y multimedia propias de Internet antes mencionadas, con el fin de aproximar al periodismo deportivo al periodismo de datos, también denominado "periodismo de base datos". Esto no es más que una nueva disciplina profesional en la que "se trabaja con grandes volúmenes de datos, se aprovecha al máximo la visualización interactiva y se incorpora al programador al equipo periodístico para desarrollar tareas que van desde la extracción de datos y la depuración de sets de datos hasta el diseño de aplicaciones de noticias" (Crucianelli, 2013).

En este camino, pese a que todavía pueda considerarse como incipiente, ya son varios los medios de comunicación que han empezado a explotar el verdadero potencial de esta nueva técnica de representación visual de la información a través de la explotación de la ingente cantidad de datos que se generan y acumulan en el mundo del deporte.

Los primeros pasos en este sentido han correspondido a medios anglosajones como The New York Times, The Washington Post o The Guardian, que han aprovechado la celebración de grandes eventos deportivos internacionales como los Juegos Olímpicos de Londres (2012) y los de Invierno en Sochi (2014) para reforzar su cobertura informativa mediante el uso de nuevas herramientas digitales y la exploración de nuevas narrativas. A estos medios se han sumado otros proyectos unipersonales de periodistas como Nate Silver (FiveThirtyEight. com) o Bill Simmons (Grantland.com), ambas asociados dentro del conglomerado digital de la cadena $E S P N$.

\subsubsection{Largo formato}

En esa búsqueda permanente hacia la innovación narrativa del periodismo, el deporte también se ha comportado como terreno de avanzadilla procurando al resto de medios y áreas informativas claves para entender la potencialidad de las nuevas tecnologías. Así, en ese camino a la experimentación, ha resurgido con fuerza el periodismo deportivo de largo formato o Long Form Journalism, una tipología narrativa que no es nueva (publicaciones como Esquire o The New Yorker cultivan los textos largos desde hace décadas), en la que confluyen la cantidad y la calidad, y que va a más en los soportes digitales.

El renacimiento del largo formato, del gusto por ofrecer textos largos para lecturas reposadas, diversos autores lo sitúan en los años 2007 o 2008, en un momento en el que surgen Longform y Longreads, sitios web contenedores de artículos de larga extensión publicados a lo largo de los años en diversos medios impresos, principalmente estadounidenses. Estos abrieron la mirada a editores de empresas periodísticas, que decidieron lucir todas las posibilidades del storytelling digital en piezas vistosas firmadas por algunos de sus 
redactores estrella, las cuales comenzaron a publicarse también como un reclamo para reforzar la comercialización de su marca (Hyatt, 2014).

Desde 2013 se ha acentuado la apuesta de medios digitales de varios países por un periodismo narrativo caracterizado por la presentación de historias cautivadoras y atractivas, con alrededor de 10.000 palabras y con estructura dividida en capítulos, y, muy especialmente, por la incorporación de elementos multimedia e interactivos (vídeos, fotografías, audios y gráficos) que aparecen y se van abriendo a medida que avanzamos en la lectura haciendo scroll; todo ello con el fin de amenizar la lectura y crear efectos sorprendentes para atrapar la atención del usuario-lector y de convertirla en una verdadera experiencia para el usuario.

Las nuevas narrativas digitales han hallado en el ámbito deportivo un terreno de experimentación pujante desde que a finales de 2012 The New York Times publicase el trabajo multimedia "Snow Fall: The Avalanche at Tunnel Creek", la historia trágica de un grupo de dieciséis esquiadores expertos atrapados en un alud en las montañas Cascade en el Estado de Washington que escribió el reportero John Branch.

Incluso con anterioridad a este hito periodístico, varios medios deportivos de Estados Unidos comenzaron a aplicar este tipo de innovaciones narrativas en sus reportajes de largo formato para recrear hazañas o contar historias de héroes desconocidos u olvidados. Uno de ellos, ESPN, elaboró, dentro de su serie "Outside The Lines" (OTL) y unos meses antes de "Snow Fall”, “The Long, Strange Trip of Dock Ellis", pieza multimedia sobre una figura del béisbol norteamericano y basada también en la narrativa scroll (scrollytelling).

Además de $E S P N$, otros medios digitales han avanzado en su apuesta por el largo formato y las nuevas narrativas reforzando sus departamentos gráficos y multimedia y creando sitios específicos para alojar este tipo de reportajes. Así lo hizo en 2012 SB Nation y un año más tarde tanto la edición web de la prestigiosa revista Sports Illustrated como el diario deportivo francés L'Equipe.

\section{Conclusiones}

Internet ha permitido a los periodistas sacar a la luz toda su creatividad para presentar sus historias de una forma innovadora con el fin de satisfacer las nuevas exigencias del entorno 2.0. y las expectativas de un receptor que ya es participativo y tiene capacidad para tomar la iniciativa.

En este contexto de cambio estructural de las empresas de comunicación, iniciado a raíz de la irrupción de los soportes digitales, el periodismo deportivo ha sido capaz de reinventarse incorporando nuevas herramientas tecnológicas aplicadas a las tareas periodísticas para ofrecer formatos renovados que empiezan a marcar tendencias en otras áreas informativas. Este ámbito periodístico despunta como un terreno innovador, pero también como un área de emprendimiento. Junto con los medios tradicionales, que siguen apostando por 
el deporte como una de las bases de su negocio por el amplio seguimiento que este tipo de noticias tienen entre el público, han aparecido nuevos medios puestos en marcha por periodistas o grupos de periodistas.

Estos proyectos emprendedores, más o menos superespecializados en sus temáticas (pero todos ellos dirigidos a cubrir nuevos nichos del mercado informativo), están llamados a abrir un nuevo campo de experimentación y de análisis en el ámbito del periodismo deportivo en los próximos años.

\section{Fuentes consultadas}

Alcoba, A. (2005). Periodismo deportivo. Madrid: Síntesis.

Andrews, P. (2005). Sports Journalism. Londres: Sage.

Asociación de la prensa de Madrid (2013). Informe Anual de la Profesión Periodística. Madrid: APM

Boyle, R. (2006). Sports Journalism. Context and Issues. Londres: Sage.

Crucianelli, S. (2013). “¿Qué es el periodismo de datos?”. Cuadernos de Periodistas. Extraída el 15/II/2014 desde http://www.cuadernosdeperiodistas.com/que-es-elperiodismo-de-datos/

Edo, C. (2009). "La noticia en Internet: Cibermedios, blogs y entornos comunicativos emergentes". Estudios de Periodística, núm. XV. Extraída el 28/III/2014 desde http:// www.bocc.ubi.pt/pag/edo-concha-internet-como-soporte-informativo.pdf

Ferrara, L. (2014, marzo 13). "What does it take to cover big-time sports?”. Extraída el 14/ III/2014 desde http://www.poynter.org/latest-news/top-stories/243258/what-does-it-taketo-cover-big-time-sports/

Hernández, A.; Osorio, J. y Zapata, D. (2013). Periodismo deportivo: Entre líneas, voces e imágenes. Medellín: Imprenta Departamental de Antioquia.

Hyatt, A. (2014). "The future of digital longform". Tow Center for Digital Journalism. Extraída el 14/II/2014 desde http://longform.towcenter.org/

Marrero, L. (2008). "El reportaje multimedia como género del periodismo digital actual. Acercamiento a sus rasgos formales y de contenido". Revista Latina de Comunicación Social, núm. 63. Extraída el 25/I/2014 desde http://dialnet.unirioja.es/servlet/ articulo? codigo $=2702840$ 
Marrero Rivera, O. (2011). Fundamentos del periodismo deportivo. San Juan de Puerto Rico: Terranova.

Matthews, L. y Anwar, D. (2013). "Social Media and Sports Journalism: How is the rise of Twitter affecting football Journalism". En Fowler-Watt, K. y Allan, S. (coord.). Journalism: New Challenges. Bournemouth: Centre for Journalism \& Communication Research, Bournemouth University

Pellicer, M. (2014). “10 Tendencias sobre periodismo para 2014”. Extraída el 13/I/2014 desde http://miquelpellicer.info/2013/12/tendencias-sobre-periodismo-para-2014/

Ramos, R. (2014, enero 7). "Ramos Returns: Anticipating 2014's top social media trends". National Sports Journalism Center. Extraída el 13/I/2014 desde http://sportsjournalism. org/sports-media-news/ramos-returns-anticipating-2014s-top-social-media-trends/

Rojas Torrijos, J. L.

_(2013). "Periodismo deportivo. Hacia la innovación y el emprendimiento en la red", pp.

197-247. En Sobrados, M. (coord.). Presente y futuro en el periodismo especializado. Madrid: Fragua.

_(2011). Periodismo deportivo de calidad. Madrid: Fragua.

Rowe, D. (2013). "Reflections on Communication and Sport: On Nation and Globalization". Communication \& Sport, núm. 1, pp. 18-29.

Salaverría, R. y García Avilés, J. (2008). "La convergencia tecnológica en los medios de comunicación: retos para el periodismo". Trípodos, núm. 23. Extraída el 30/III/2014 desde http://dspace.unav.es/dspace/bitstream/10171/5071/1/154114.pdf

Sharp, N. (2013). "The future of longform”. Columbia Journalism Review. Extraída el 20/ III/2014 desde http://www.cjr.org/behind_the_news/longform_conference.php?page=all

Wanta, W. (2012). "Reflections on Communication and Sport: On Reporting and Journalist". Communication \& Sport, núm. 1, pp. 76-87. 